\title{
0026. Voluntary activation of the sympathetic nervous system and attenuation of the innate immune response in humans
}

\author{
M Kox ${ }^{1,2,3^{*}}$, LT van Eijk $k^{1,3}$, J Z Zwaag ${ }^{1,3}$, J van den Wildenberg ${ }^{1,3}$, FCJG Sweep ${ }^{4}$, JG van der Hoeven ${ }^{1,3}$, P Pickkers ${ }^{1,3}$ \\ From ESICM LIVES 2014 \\ Barcelona, Spain. 27 September - 1 October 2014
}

\section{Introduction}

Excessive or persistent pro-inflammatory cytokine production plays a central role in a variety of inflammatory conditions. Acute activation of the sympathetic nervous system attenuates innate immunity. However, both the autonomic nervous system and innate immune system are regarded as systems that cannot be voluntarily influenced.

\section{Objectives}

To evaluate the effects of a training program on the autonomic nervous system and innate immune response.

\section{Methods}

We performed a parallel randomized controlled study in healthy male volunteers. Subjects were randomized to receive either a 10-day training program involving meditation (third eye meditation), breathing techniques (i.a., cyclic hyperventilation followed by breath retention), and exposure to cold (i.a., immersions in ice cold water), or no training. Subjects in both groups ( $\mathrm{n}=12$ per group) underwent experimental human endotoxemia (intravenous administration of $2 \mathrm{ng} / \mathrm{kg}$ E. Coli lipopolysaccharide [LPS]) during which the trained individuals practiced the learned techniques.

\section{Results}

Practicing the learned techniques resulted in intermittent respiratory alkalosis and hypoxia resulting in significantly increased plasma epinephrine levels (Figure 1). In the trained group, plasma levels of the anti-inflammatory cytokine IL-10 increased more rapidly after LPS

${ }^{1}$ Radboud University Medical Center, Intensive Care Medicine, Nijmegen, Netherlands

Full list of author information is available at the end of the article administration, correlated strongly with preceding epinephrine levels $(\mathrm{r}=0.82, \mathrm{p}=0.001)$, and were higher (Figure 2). Levels of pro-inflammatory mediators TNF- $\alpha$, IL-6, and IL-8 were lower in the trained group (Figure 2) and correlated negatively with IL-10 levels $(\mathrm{r}=-0.71, \mathrm{p}=$ $0.01 ; \mathrm{r}=-0.59, \mathrm{p}=0.045 ; \mathrm{r}=-0.71, \mathrm{p}=0.01$, respectively).

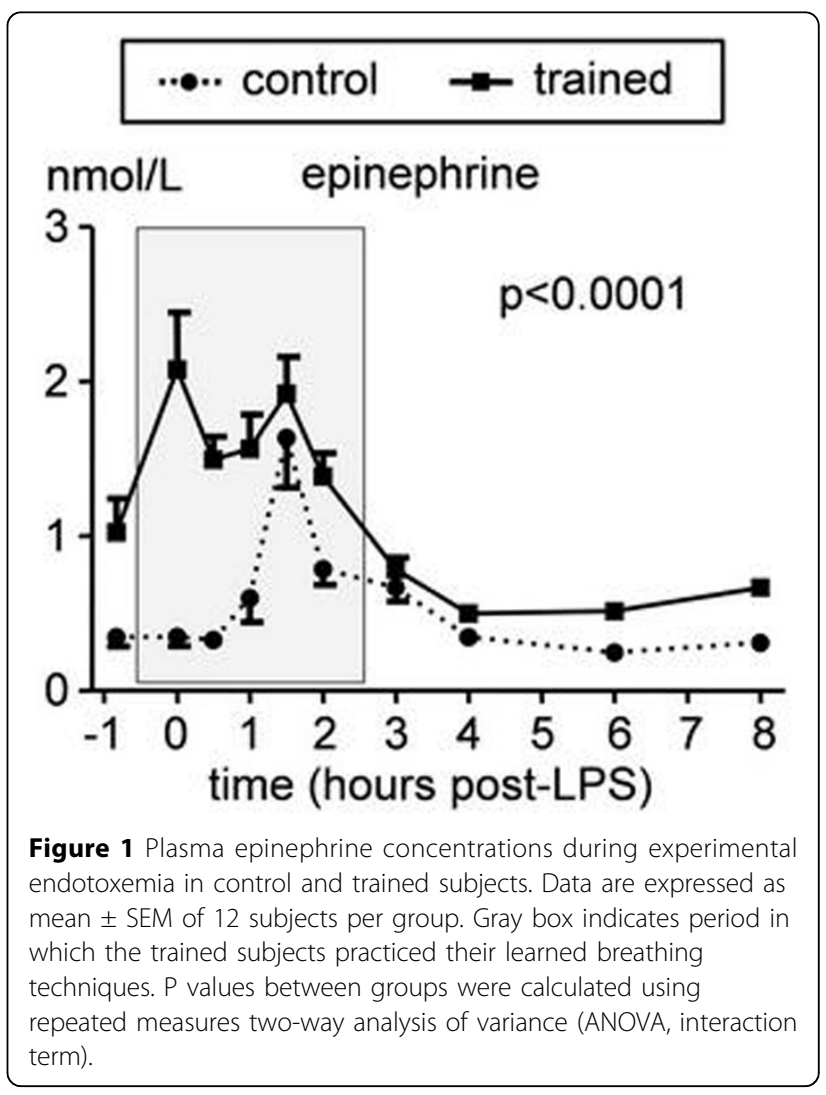




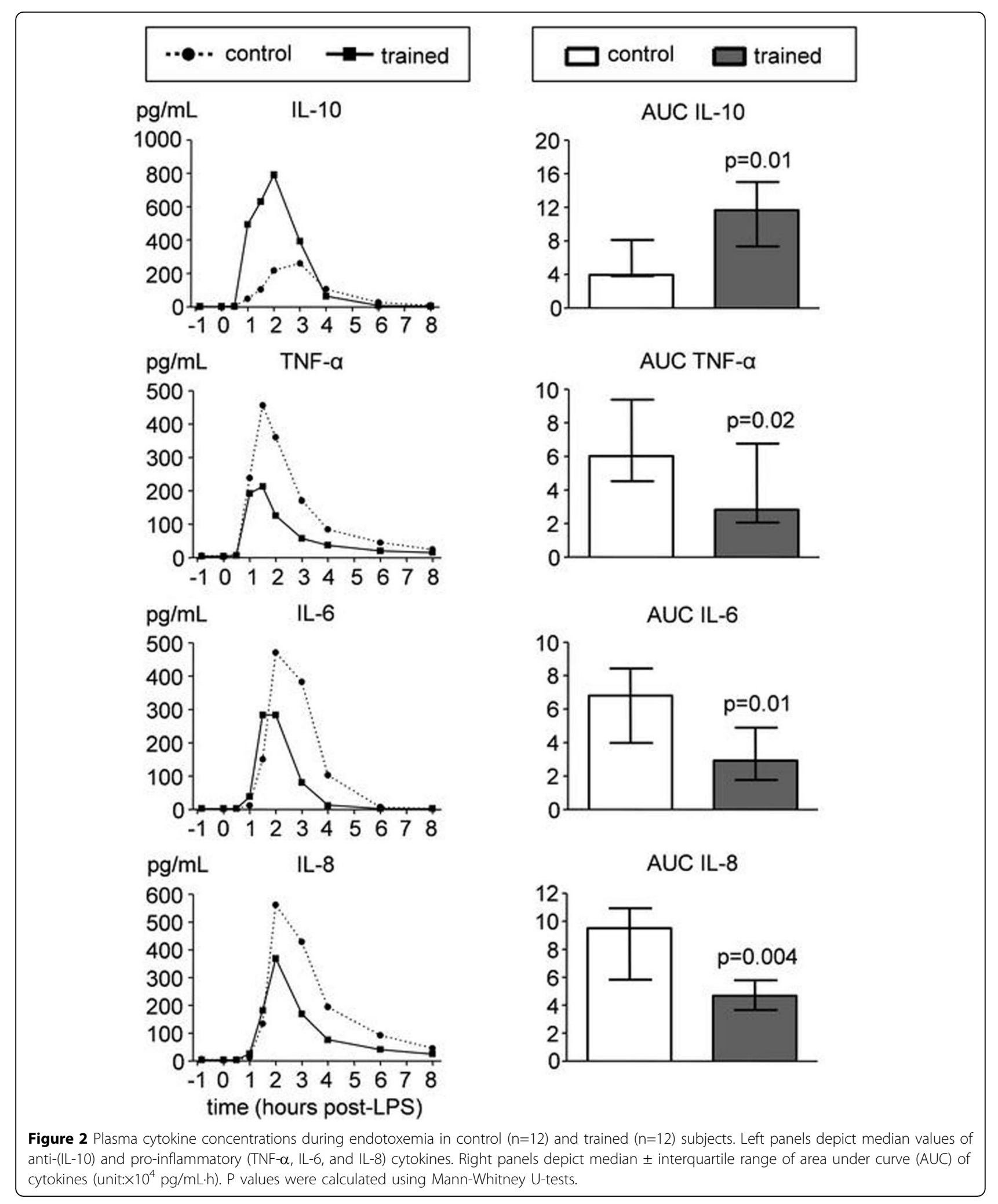


Finally, LPS-induced flu-like symptoms and fever were blunted in the trained group.

\section{Conclusions}

Voluntary activation of the sympathetic nervous system results in epinephrine release and subsequent suppression of the innate immune response in humans in vivo. These results could have important implications for the treatment of a variety of conditions associated with excessive or persistent inflammation.

\section{Grant acknowledgment}

This study was supported by a Serendipity Grant from Reumafonds (http:// www.reumafonds.nl).

\section{Authors' details}

${ }^{1}$ Radboud University Medical Center, Intensive Care Medicine, Nijmegen, Netherlands. ${ }^{2}$ Radboud University Medical Center, Anesthesiology, Nijmegen, Netherlands. ${ }^{3}$ Nijmegen Institute for Infection, Inflammation and Immunity, Nijmegen, Netherlands. ${ }^{4}$ Radboud University Medical Center, Laboratory Medicine, Nijmegen, Netherlands.

Published: 26 September 2014

doi:10.1186/2197-425X-2-S1-O2

Cite this article as: Kox et al:: 0026. Voluntary activation of the sympathetic nervous system and attenuation of the innate immune response in humans. Intensive Care Medicine Experimental 20142 (Suppl 1):O2.

\section{Submit your manuscript to a SpringerOpen ${ }^{\mathcal{D}}$ journal and benefit from:}

- Convenient online submission

- Rigorous peer review

- Immediate publication on acceptance

- Open access: articles freely available online

- High visibility within the field

- Retaining the copyright to your article

Submit your next manuscript at $>$ springeropen.com 